\title{
Assessment of Modern Health Care Opportunities in Management of Medical Care Safety
}

\section{Yuriy Voskanyan" ${ }^{1}$, Irina Shikina ${ }^{2,3 *}$, Fedor Kidalov ${ }^{4}$ and David Davidov ${ }^{2}$}

${ }^{1}$ Russian Medical Academy of Continuing Professional Education of the Ministry of Health of Russia, Moscow, Russia ${ }^{2}$ Central Research Institute for Organization and Informatization of Medical care at the Ministry of Health of Russia, Moscow, Russia ${ }^{3}$ Central State Medical Academy Office of the President of the Russian Federation, Moscow, Russia ${ }^{4}$ State Government Institution of Moscow City "Informational-Analytical Center for medical care, Moscow, Russia * Corresponding Author: Irina Shikina, Central Research Institute for Organization and Informatization of Medical care at the Ministry of Health of Russia, Moscow, Russia.

Received: September 13, 2019; Published: October 15, 2019

Yuriy Voskanyan Orcid ID: https://orcid.org/0000-0003-2962-2818

Irina Shikina Orcid ID: http://orcid.org/0000-0003-1744-9528

Fedor Kidalov Orcid ID: http://orcid.org/0000-0003-4914-8164

David Davidov Orcid ID: https://orcid.org/0000-0003-4576-6854

DOI: 10.31080/ASMS.2019.03.0438

\begin{abstract}
In the article the system reasons of adverse events in modern health care (latent threats) are taken into account, key approaches to management of medical care safety. The authors understand them as the relation of chances of advantage and harm for the patient taking into account risk of adverse events at personnel and risk of adverse changes of the production and external environment are offered are considered. In the developed countries the additional harm connected with health care delivery is registered at $10.6 \%$ of the hospitalized patients and less than in $50 \%$ of cases belongs to preventable harm category caused by medical mistakes. In other cases its emergence caused by patient behavior, influence of the production environment, imperfection of medical technologies and corporate management systems. In structure of the reasons of hospital lethality the share of the harm connected with health care delivery is 24.9\%. Effective management of medical care safety is possible only with interaction of four subjects: government (recognition at the legislative level of the fact of inevitability of medical mistakes taking into account their system reasons, a guarantee of rights and freedoms to medical personnel at registration of adverse events, formalization of the rights, duties and responsibility of the patient, definition of health care as services sectors of high risk, financing of the additional actions connected with safety management), governing bodies of health care (development and implementation of government programs in the field of safety management of medical care), societies (participation in a discussion, adoption of declarations, development of regulations, partnership at delivery of health care) and the most medical organization. The modern strategy of safety management of medical care in the medical organization includes formation of a new safety culture (as element of corporate culture), introduction of accounting system of threats of incidents, and risks, creation of a control system of safety on the basis of risk stratification of incidents.
\end{abstract}

Keywords: Medical Care Safety; Latent Threats; Medical Mistakes, Adverse Events

\section{Introduction}

International studies in the field of medical care safety demonstrate the special role of medical errors and related adverse events, as well as unexpected deaths in the structure of hospital mortality and population mortality in developed countries. The key issues in additional harm risk management include definition of the es- sence of medical care safety, assessment of the problem severity, identification of systemic reasons for adverse events, formation of a new culture of safety, development, implementation and standardization of effective solutions taking into account the probability of incidents in medicine and the severity of their consequences $[1,2]$. 
The authors have formulated a new approach to the definition of the term "medical care safety"; the epidemiology of medical carerelated events have been studied and the basic principles of modern strategy of adverse event risk management in medicine have been formulated. Adverse events included unintentional physical or psychological trauma (additional harm), which was most likely related to medical care rather than the course of the main disease or concomitant diseases [3-6]. Information search was carried out by two researchers independently over a period of $1990-2017$ using medical databases MEDLINE, Cochrane Collaboration; EMBASE, SCOPUS, ISI Web of Science. For the analysis, prospective and retrospective observational studies of high methodological quality were used, which presented data on the frequency and severity of adverse events in multispecialty short-stay hospitals. The frequency of new cases of adverse events (incidence) as well as the percentages of adverse events are shown together with confidence intervals at the $95 \%$ probability of accepting the null hypothesis. Published source data pooling was carried out in a meta-analysis, the mathematical model of which was determined depending on the statistical heterogeneity index $\mathrm{I}^{2}$. In similar studies, the main principles of medical care management were evaluated. The authors necessarily took into account the relation between the principles used and the possibility of managing the systemic causes of additional harm.

\section{Result and Discussion}

Safety, along with clinical effectiveness and economic efficacy, is an important attribute of the medical care quality. However, it is necessary to strictly define the limits of this term. The majority of definitions (US Institute of Medicine, US Agency for Healthcare Research and Quality, World Health Organization etc.) connect the term of safety with the lack of unnecessary harm, minimization of its probability, or with the lack of unnecessary risk of adverse events [1]. All such definitions raise new questions related to the need to interpret such concepts as "unnecessary harm", "unnecessary risk", etc. However, most importantly, none of these definitions can quantitatively assess the degree of safety, which makes the management of adverse events difficult to implement. We believe that the medical care safety can be defined as the benefit/risk ratio when providing medical care. The mathematical expression of the harm will be its risk, which is the product of probability of an adverse event by the severity of its consequences. The mathemati- cal expression of the benefit will be the probability of a planned favorable clinical outcome in the absence of the risk of additional harm. Without going into details of mathematical calculations using the values of the probability and rank coefficients of the assessment of the harm severity and the grade of the benefit, we will pay attention only to the fact that, from our point of view, it is not correct to eliminate reasonable risk of the concept "medical care safety". After all, is there any difference for the patient why he/she got hurt rather than benefited from medical interventions in which there was a reasonable risk? It was the disagreement of scientists with this "reasonable risk" that led to the rapid development of medical technologies, including surgery and drug therapy, which significantly reduced the amount of "reasonable risk" and significantly expanded the scope of their application in the target patient cohort. Next, it should be emphasized that the medical care safety is a complex concept that includes four components depending on the object of the potential risk of harm: patient's safety (unintentional physical and/or psychological trauma), staff safety (biological accidents, radiation exposure etc.), internal environment safety (high level of physical factors, pollution, state of the building and engineering systems etc.), safety of the environment (the impact of physical factors, chemical pollution etc.). This is what distinguishes safety in medicine from safety in other areas of economic activity where there are only three components (personnel, internal or external environment). Therefore, we suggest defining the term "medical care safety" as the ratio of the benefit for the patients and the risk of harm to the patient and medical staff, as well as the risk of unfavorable changes in the internal and external environment.

To assess the incidence and severity of additional harm (adverse events) when providing medical care, we selected 14 publications of high methodical quality from 9 countries: USA, Canada, UK, Denmark, New Zealand, Netherlands, Spain, Norway, Brazil. In these articles, the information about the results of inpatient treatment of 124,458 patients in 197 short-stay hospitals was analyzed. The index of statistical heterogeneity $\mathrm{I} 2$ of the source data was equal to 0.37 , so a fixed effects model based on binary data was chosen for the analysis. The cumulative probability of adverse events in inpatients was $10.6 \%$ of the total number of hospitalized patients [3-16] (Table 1). 


\begin{tabular}{|c|c|c|c|c|}
\hline Author, year of publication & Country & Number of hospitals & Number of observations & Frequency, \% (95\% CI) \\
\hline \multicolumn{5}{|l|}{ Retrospective studies } \\
\hline Brennan T., et al. 1991 [3] & USA (Harvard) & 51 & 30,195 & $3.7(3.5-3.9)$ \\
\hline Wilson R., et al. 1995 [4] & Australia & 28 & 14,210 & $16.6(15.9-17.2)$ \\
\hline Thomas E., et al. 2000 [5] & $\begin{array}{l}\text { USA (Utah, } \\
\text { Colorado) }\end{array}$ & 28 & 14,565 & $5.4(5.0-5.8)$ \\
\hline Vincent C., et al. 2001 [6] & United Kingdom & 2 & 1,014 & $108(8.9-12.8)$ \\
\hline Schioler T., et al. 2001 [7] & Denmark & 17 & 1,097 & $10.4(8.6-12.2)$ \\
\hline Davis P., et al. 2002 [8] & New Zealand & 13 & 6,579 & $12.9(12.1-13.7)$ \\
\hline Baker G., et al. 2004 [9] & Canada & 20 & 3,745 & $6.8(6.0-7.6)$ \\
\hline Zegers M., et al. 2009 [10] & Netherlands & 21 & 7,926 & $8.4(7.8-9.0)$ \\
\hline Landrigan C., et al. 2010 [11] & $\begin{array}{l}\text { USA (North } \\
\text { Carolina) }\end{array}$ & 10 & 2,341 & $18.1(16.5-19.6)$ \\
\hline Classen D., et al. 2011 [12] & $\begin{array}{c}\text { USA } \\
\text { (Massachusetts) }\end{array}$ & 3 & 795 & $33.2(29.9-36.5)$ \\
\hline Deilkas E., et al. 2015 [13] & Norway & 20 & 40,581 & $14.5(14.3-15.0)$ \\
\hline \multicolumn{5}{|l|}{ Prospective studies } \\
\hline Andrews L., et al. 1997 [14] & Spain & 3 & 1,047 & $17.7(15.4-20.0)$ \\
\hline Wanzel K., et al. 2000 [15] & Canada & 1 & 192 & $39.1(32.2-46.0)$ \\
\hline Szlief C., et al. 2012 [16] & Brazil & 1 & 171 & $55.0(47.5-62.4)$ \\
\hline Meta-analysis & - & 197 & 124,458 & $10.6(10.5-10.8)$ \\
\hline
\end{tabular}

Table 1: Probability of adverse events.

Most of them (41.3\%) were related to surgery, $14.4 \%$ - with drug therapy, 9.8\% - with late or incorrect diagnosis, 9.1\% - ma- nipulations; 8.4\% - incorrect treatment plan [3-5, 9-10, 15] (Table 2).

\begin{tabular}{|c|c|c|c|c|c|c|c|}
\hline \multirow{3}{*}{$\begin{array}{l}\text { Types of medical } \\
\text { interventions }\end{array}$} & \multicolumn{6}{|c|}{ Source } & \multirow[b]{2}{*}{$\begin{array}{c}\text { Meta analysis: } \\
\text { Percentage \% } \\
\text { (95\% CI) }\end{array}$} \\
\hline & $\begin{array}{c}\text { Brennan T., } \\
\text { et al. } \\
1991 \text { [3] } \\
(n=1,117)\end{array}$ & $\begin{array}{c}\text { Wilson R., } \\
\text { et al. } \\
1995 \text { [4] } \\
(\mathrm{n}=2,952)\end{array}$ & $\begin{array}{c}\text { Thomas E., } \\
\text { et al. } \\
2000 \text { [5] } \\
(\mathrm{n}=787)\end{array}$ & $\begin{array}{l}\text { Wanzel M., } \\
\qquad \text { et al. } \\
2000 \text { [15] } \\
(\mathrm{n}=32)\end{array}$ & $\begin{array}{c}\text { Baker G., et al. } \\
\begin{array}{c}2004 \text { [9] } \\
(n=360)\end{array}\end{array}$ & $\begin{array}{l}\text { Zegers M., } \\
\text { et al. } \\
2009[10] \\
(n=744)\end{array}$ & \\
\hline & \multicolumn{6}{|c|}{ Percentage \% } & \\
\hline Surgery & 47.7 & 39.3 & 44.9 & 31.2 & 34.2 & 54.2 & $41.3(40.1-42.6)$ \\
\hline Manipulation & 7.0 & 6.7 & 13.5 & 9.4 & 7.2 & 17.0 & $9.1(8.4-9.8)$ \\
\hline Drug therapy & 19.4 & 8.4 & 19.3 & 15.6 & 23.6 & 15.3 & $14.4(13.5-15.3)$ \\
\hline $\begin{array}{l}\text { Incorrect treatment } \\
\text { plan }\end{array}$ & 7.5 & 9.3 & 4.3 & 15.6 & 11.9 & 5.1 & $8.4(7.7-9.1)$ \\
\hline $\begin{array}{l}\text { Late or incorrect } \\
\text { diagnosis }\end{array}$ & 8.1 & 10.6 & 6.9 & 28.1 & 10.6 & 6.3 & $9.8(9.0-10.5)$ \\
\hline Other interventions & 10.3 & 25.7 & 11.1 & - & 12.5 & 2.1 & $17.0(16.1-18.0)$ \\
\hline Total & 100.0 & 100.0 & 100.0 & 100.0 & 100.0 & 100.0 & - \\
\hline
\end{tabular}

Table 2: Types of medical interventions and percentages of adverse events. 
Assessment of Modern Health Care Opportunities in Management of Medical Care Safety

Only $45.5 \%$ of adverse events were considered preventable [3-4,610,15,17-20], and in $27.7 \%$ of cases additional harm was caused by negligence in the actions of the personnel [3,5,21] (Table 3 and 4).

\begin{tabular}{|c|c|c|c|}
\hline Author, year of publication & $\begin{array}{c}\text { Total number of } \\
\text { events }\end{array}$ & $\begin{array}{c}\text { Number of preventable } \\
\text { events }\end{array}$ & Percentage \% (95\% CI) \\
\hline \multicolumn{4}{|l|}{ Hospital } \\
\hline Brennan T., et al.1991 [3] & 1,117 & 308 & $27.6(25.0-30.2)$ \\
\hline McGuire H. et al.,1992 [17] & 2,409 & 1,180 & $49.0(47.0-51.0)$ \\
\hline O’Neil A., et al.1993 [18] & 133 & 83 & $62.4(54.2-70.6)$ \\
\hline Wilson R., et al.1995 [4] & 2,302 & 1,178 & $51.2(49.1-53.2)$ \\
\hline Wanzel K., et al.2000 [15] & 192 & 88 & $45.8(38.8-52.9)$ \\
\hline Vincent C., et al.2001 [6] & 119 & 57 & $47.9(38.9-56.9)$ \\
\hline Schioler T., et al.2001 [7] & 114 & 46 & $40.3(31.3-49.4)$ \\
\hline Davis P., et al.2002 [8] & 850 & 315 & $37.1(33.8-40.3)$ \\
\hline Baker G., et al.2004 [9] & 289 & 106 & $36.7(31.1-42.2)$ \\
\hline Zegers M., et al.2009 [10] & 663 & 283 & $42.7(38.9-46.4)$ \\
\hline \multicolumn{4}{|l|}{ Outpatient clinic } \\
\hline Singh H., et al.2004 [19] & 308 & 108 & $35.1(29.7-40.4)$ \\
\hline Woods D., et al.2007 [20] & 2,608 & 1,296 & $49.7(47.8-51.6)$ \\
\hline Meta-analysis & 11,104 & 5,048 & $45.5(44.5-46.4)$ \\
\hline
\end{tabular}

Table 3: Preventable dverse events.

Severe harm and disability in patients with adverse events were observed in $11.8 \%$ cases, and unexpected death - in $5.3 \%$ of cases [4-6,8-11,15,22] (Table 5).
The analysis of cumulative frequency of hospital mortality rate in a number of countries showed quite a large percentage of unexpected death caused by adverse events - 24.9\% [4;6;9;10; 22-29] (Table 6).

\begin{tabular}{|c|c|c|c|c|c|}
\hline \multirow{3}{*}{ Source } & \multirow{3}{*}{$\begin{array}{c}\text { Number of } \\
\text { adverse events }\end{array}$} & \multicolumn{4}{|c|}{ Severity of harm } \\
\hline & & \multicolumn{2}{|c|}{ Severe harm and disability } & \multicolumn{2}{|c|}{ Death } \\
\hline & & $\begin{array}{l}\text { Absolute } \\
\text { number }\end{array}$ & $\begin{array}{c}\text { Percentage \% } \\
\left(95 \% \mathrm{CI}^{*}\right)\end{array}$ & $\begin{array}{c}\text { Absolute } \\
\text { number }\end{array}$ & $\begin{array}{l}\text { Percentage \% } \\
\text { (95\% CI) }\end{array}$ \\
\hline Wilson R., et al. 1995 [4] & 2,324 & 315 & $13.7(12.3-15.1)$ & 112 & $4.9(4.0-5.8)$ \\
\hline Thomas E., et al.2000 [5] & 787 & 130 & $16.6(13.9-19.1)$ & 52 & $6.6(4.9-8.3)$ \\
\hline Wanzel K., et al. 2000 [15] & 144 & 10 & $6.9(2.8-11.1)$ & 2 & $1.4(0.5-3.3)$ \\
\hline Vincent C., et al. 2001 [6] & 110 & 7 & $6.4(1.8-10.9)$ & 9 & $8.2(3.1-13.3)$ \\
\hline Davis P., et al.2003 [8] & 850 & 87 & $10.2(8.2-12.3)$ & 38 & $4.5(3.1-5.9)$ \\
\hline Baker G., et al.2004 [9] & 289 & 14 & $4.8(2.4-7.3)$ & 46 & $15.9(11.7-20.1)$ \\
\hline Andrews J., et al.2006 [22] & 655 & 90 & $13.7(11.1-16.4)$ & 15 & $2.3(1.1-3.4)$ \\
\hline Zegers M., et al.2009 [10] & 663 & 33 & $5.0(3.3-6.6)$ & 52 & $7.8(5.8-9.9)$ \\
\hline Landrigan C., et al.2010 [11] & 588 & 67 & $11.4(8.8-14.0)$ & 14 & $2.4(1.1-3.6)$ \\
\hline Meta-analysis & 6,388 & 753 & $11.8(11.0-12.6)$ & 340 & $5.3(4.8-5.9)$ \\
\hline
\end{tabular}

Table 5: Severe harm, disability and unexpected death in case of an adverse event. 


\begin{tabular}{|c|c|c|c|c|}
\hline Source & Country & $\begin{array}{c}\text { Percentage of } \\
\text { unexpected deaths \% } \\
\text { (proportion) }\end{array}$ & $\begin{array}{c}\text { Hospital mortality } \\
\text { rate } \% \\
\text { (proportion) }\end{array}$ & $\begin{array}{l}\text { Percentage of unexpected } \\
\text { deaths of hospital } \\
\text { mortality rate } \%\left(95 \% \mathrm{CI}^{*}\right)\end{array}$ \\
\hline Wilson R., et al.1995 [4] & Australia & $0.79(112 / 14210)$ & $1.90(270 / 14210)$ & $41.5(35.6-47.4)$ \\
\hline Vincent C., et al.2001 [6] & \multirow[b]{2}{*}{ United Kingdom } & $0.89(9 / 1014)$ & - & \multirow[b]{2}{*}{$26.6(21.8-31.3)$} \\
\hline Campbell M., et al.2011 [23] & & - & $\begin{array}{c}3.35 \\
(1581358 / 47172030)\end{array}$ & \\
\hline Baker G., et al.2004 [9] & \multirow[b]{2}{*}{ Canada } & $1.23(46 / 3745)$ & - & \multirow[b]{2}{*}{$34.2(30.0-38.3)$} \\
\hline $\begin{array}{l}\text { Canad. Inst. of Health Inf., } \\
2005[25]\end{array}$ & & - & $\begin{array}{c}3.60 \\
(109989 / 3058901)\end{array}$ & \\
\hline Andrews J., et al.2006 [22] & \multirow[b]{2}{*}{ Spain } & $0.27(15 / 5624)$ & - & \multirow[b]{2}{*}{$20.8(14.9-26.6)$} \\
\hline Aiken L., et al. 2014 [26] & & - & $1.3(283 / 21520)$ & \\
\hline Zegers M., et al. 2009 [10] & \multirow[b]{2}{*}{ Netherlands } & $0.66(52 / 7926)$ & - & \multirow[b]{2}{*}{$17.2(14.0-20.4)$} \\
\hline Jarman B., et al.2010 [27] & & - & $3.84(90873 / 2363332)$ & \\
\hline Makary M., et al.2016 [28] & USA & $\begin{array}{c}0.71 \\
(251454 / 35416020) \\
\end{array}$ & - & \multirow[b]{2}{*}{$34.8(29.3-40.3)$} \\
\hline Hall M., et al.2013 [29] & USA & - & $\begin{array}{c}2.04 \\
(715000 / 35049019)\end{array}$ & \\
\hline Meta-analysis & - & $\begin{array}{c}0.71 \\
(251688 / 35448539)\end{array}$ & $\begin{array}{c}2.85 \\
(2497773 / 87679012)\end{array}$ & $24.9(24.9-24.9)$ \\
\hline
\end{tabular}

Table 6: Hospital mortality rate and unexpected deaths.

The authors from the Johns Hopkins Hospital [28] showed that adverse events form the third cause of mortality in the USA accounting for every tenth death in the country (Table 7).

\begin{tabular}{|l|c|c|}
\hline Cause of death (2013) & $\begin{array}{c}\text { Number of } \\
\text { deaths }\end{array}$ & $\begin{array}{c}\text { Percentage \% } \\
\text { (95\% CI) }\end{array}$ \\
\hline Cardiovascular disorders & 614,348 & $23.6(23.6-23.7)$ \\
\hline Neoplasms & 591,699 & $22.8(22.7-22.8)$ \\
\hline $\begin{array}{l}\text { Harm related to provision of } \\
\text { medical care }\end{array}$ & 251,454 & $9.7(9.7-9.7)$ \\
\hline Chronic respiratory diseases & 147,101 & $5.7(5.6-5.7)$ \\
\hline Unintentional damage & 136,053 & $5.2(5.2-5.3)$ \\
\hline Cerebrovascular accident & 133,103 & $5.1(5.1-5.1)$ \\
\hline $\begin{array}{l}\text { Alzheimer's disease-related } \\
\text { complications }\end{array}$ & 93,541 & $3.6(3.6-3.6)$ \\
\hline Diabetes-related complications & 76,488 & $2.9(2.9-3.0)$ \\
\hline Influenza and pneumonia & 55,227 & $2.1(2.0-2.0)$ \\
\hline Kidney diseases & 48,146 & $1.8(1.8-1.9)$ \\
\hline Suicide & 42,773 & $1.6(1.6-1.7)$ \\
\hline Other causes & 407,060 & $15.7(15.6-15.7)$ \\
\hline TOTAL & $2,596,993$ & 100.0 \\
\hline
\end{tabular}

Table 7: Mortality rate structure in the US population (Makary M. et al., 2016).
The causes and the mechanism of development of adverse events were studied in 20 publications of high methodological quality. The main reasons for additional harm were latent threats. These threats are not directly related to the source of the adverse event, are constant and do not carry any danger if they are inactive [21,30,31]. Under certain conditions, a latent threat is activated and turns into a dangerous situation (active threat 1), which, in its turn, lead to the development of dangerous processes (active threats 2) - unsafe actions (errors) of the personnel, unsafe patient behavior, unsafe processes in the environment in which medical care is provided. The result of a dangerous situation are dangerous events (incidents), which in the international literature are called incidents. The incident might cause harm to the patient (an incident without sequelae) or end with harm (an incident with sequelae) or might lead to the patient's death (a critical incident) [30-32].

Latent threats exist and transform into adverse events at three levels: at the level of the staff, at the level of the patient and at the level of the environment. At each of these levels, global latent threats (that are present regardless of the site of medical care provision and its profile) and specific latent threats (caused by the specific site of medical care provision and its profile) have been described. Quite often, a transformation of a latent threat moves 
from one level to the other [32-34]. In most cases, the incidents and resulting adverse events are the result of the transformation of several latent threats followed by a series of active threats that coincide in time and space [32].

So far, four groups of global latent threats have been studied at the staff level: related to personnel management (management system, procedural rules, communication (including identification and verification), team work); associated with personnel selection (staff positions, staff turnover, employment of part-time employees) associated with personnel competence (low baseline competence, freedom in the implementation of official duties, acquired competence deficiency) related to mental state and physiological condition of the personnel (personal problems and disease, a distrust in leadership and procedural rules, low level of commitment to procedural norms) [30,33-35]. These threats turn into a dangerous situation during the provision of medical care and lead to dangerous events - staff errors (blunder, miscalculation, omission, violation) [36,37].

Global threats at the patient level can be divided into three groups: caused by mental state and physiological condition of the patient (pain, physical and mental disorders), caused by the personal characteristics of the patient (low general educational status, insufficient level of medical literacy, low level of motivation to fulfill medical prescriptions), caused by the personal data features (coincidence of personal data). The described threats turn into a dangerous situation at the time of the patient's movement, his/ her communication with the staff, the implementation of medical prescriptions and in the process of self-monitoring of the patient's condition. As a result, dangerous events develop - incorrect actions (lack of actions) of the patient, or staff errors in the process of staff-patient interactions [33,38-41].

At the level of the environment in which medical care is provided, two groups of global latent threats have been studied: those related to the social environment and those related to the technological environment. In the technological environment, there are threats associated with the workplace (tools and objects of labor, workspace) and threats associated with the building (constructions, engineering and logistics systems). The environmental threats turn into a dangerous situation during the provision of medical care [30-32,35,38]. As a result, unsafe processes occur in the environment itself (accidents, failures, failures in the building, equipment, engineering systems, direct harmful effects of physical, chemical or biological factors). Other variants of transformation of the latent threats of the environment include unsafe patient's behavior (e.g., stumbling) or a staff error that occurred in the process of its interaction with the tools (items) of labor and workspace $[33,38,40,41]$.

\section{Conclusion}

Successful experience of safety management in developed countries has shown that the solution to this problem can not be implemented only at the level of one medical organization. A comprehensive approach at the level of the public authorities, medical care system and society is needed. In the first case, it is necessary to make significant changes in the regulatory framework. These changes should define medical care as a high-risk service, admit the fact of existence of medical errors and adverse events, guarantee medical personnel the rights and freedoms in case of detection and recording of cases of additional harm to the patient, to formalize the powers and responsibilities of the patient, to provide additional funding to ensure the target level of the patient's safety, staff and the environment. The medical care system should adopt a new safety culture taking into account the existing high probability of adverse events and systemic causes of additional harm, provide management for the development and standardization of effective solutions to prevent the risk of additional harm, justify additional funding for activities and the necessary infrastructure to ensure the target level of safety in medical organizations. At the society level, it is necessary to arrange a discussion on the issues of medical care safety, the result of which should be an understanding of the need to form a single team of healthcare providers, patients and their relatives in the process of providing medical care - a team that will provide comprehensive management control of the feasibility, timeliness, occupancy and quality of implementation of the chosen treatment plan.

The modern strategy of medical care safety management in a medical organization includes the development of a new safety culture, arrangement of the incidents and threat accounting, incident stratification, the definition of the scope of incident management and the scope of activities, the introduction of the incident investigation algorithm, the standardization of the process of preventing the transformation of a latent threat into an adverse event. The in- 
troduction of this strategy usually includes two stages. At the first stage, the described events relate to latent threats, which ended in the development of incidents and adverse events. At the second stage, all latent threats at the clinic are identified and managed including those which did not end in the development of incidents $[1,32,34,35]$.

The new safety culture, which is part of the corporate culture, is based on the following provisions: incidents and adverse events are inevitable parts of medical care, they are based on permanent systemic causes - latent threats; safety is ensured by eliminating systemic causes and guaranteed not only by individual skills of the performer, but an integrated system that provides for the creation of conditions that prevent the transformation of a latent threat into an adverse event; prevention of harm associated with the provision of medical care is proactive, which implies the management of all latent threats identified in the clinic. The level of safety culture is assessed by means of special questionnaires, taking into account the orientation to the listed values of the top management, staff awareness of safety issues, staff perception of the general level of safety, staff commitment to procedural standards and their trust in management, as well as the quality of team management and the quality of communication [1,30,32,34].

The accounting system includes obtaining information about the threats and incidents, their identification, registration, monitoring and measurement. For accounting, most countries use character encoding of threats and incidents suggested by the National Coordinating Council for Medication Error Reporting and Prevention (NCC MERP, 1998 - 2001) [1,31,33,42,43]. A big problem related to objective accounting is concealment and (or) masking of incidents and adverse events. In case of concealment, the incidents are simply not reported, in case of masking, they are interpreted as complications related to the course of the primary or concomitant diseases. The most common object of concealment and masking is an infection related to provision of medical care. Several effective solutions have been suggested in order to prevent concealment and masking of incidents: collection of information not only from medical records but also from colleagues, patients and independent auditors as well as accounting automation [30,31,33,35,38]. Another quite effective solution is a system of registration of procedure-related incidents and their consequences. An example is a system Global Trigger Tool used for this purpose in Europe and the USA. Procedure-related events include "rigid" (independent of a subjective factor) process indicators, non-typical complications, abnormal behavior and non-typical patient's condition as well as all cases of unexpected deaths. Information about a procedurerelated event is the reason for a thorough audit, as a result of which it is usually possible to reveal medical care-related incidents $[10,44,45]$.

Incidents' stratification determines the grade of their risk (a hazard class). For stratification, two main criteria measured in rank coefficients are used. They include the severity of the harm and repeatability (incidence) of the incident. The hazard class of the incident is determined in accordance with the classification proposed by experts of the UK National Healthcare System - NHS Commissioning Board Authority, which distinguishes four risk groups, each of which regulates the scope of activities, the scope of management and the possibility of further medical care provision. While investigating the incident, active and latent threats are identified and the adverse event route map is formed [32,33,35,46,47].

Prevention of transformation of the latent threat into an adverse event is achieved by the development and implementation of a management standard that envisages the elimination of preventable and minimization of the impact of unpreventable latent threats. For this purpose, a multilevel protection system envisaging the block of each stage of the latent threat transformation is normally created $[21,32,33,35,48-50]$.

\section{Bibliography}

1. Roitberg GE and Kondratova N. "Medical organization according to the international quality standards: a practical guide to implementation". Moscow (2018): 152.

2. World Health Organization. "World health statistics: monitoring health for the SDGs, Sustainable Development Goals". Geneva (2018).

3. Brennan TA., et al. "Incidence of adverse events and negligence in hospitalized patients: results of the Harvard Medical Practice Study I". The New England Journal of Medicine 324 (1991): 370-376.

4. Wilson RM., et al. "The quality in Australian medical care study". Medical Journal of Australia 163 (1995): 458-471. 
5. Thomas EJ., et al. "Incidence and types of adverse events and negligent care in Utah and Colorado". Med Care 38.3 (2000): 261-271.

6. Vincent C., et al. "Adverse events in British hospitals: preliminary retrospective record review". British Medical Journal 322.7285 (2001): 517-519.

7. Schiøler T., et al. "Incidence of adverse events in hospitals. A retrospective study of medical records". Ugeskrift for Læger 163.39 (2001): 5370-5378.

8. Davis P., et al. "Adverse events in New Zealand public hospitals I: occurrence and impact". The New Zealand Medical Journal 115.1167 (2002): U271.

9. Baker GR., et al. "The Canadian Adverse Events Study: the incidence of adverse events among hospital patients in Canada". Canadian Medical Association Journal 170.11 (2004): 16781686.

10. Zegers M., et al. "Adverse events and potentially preventable deaths in Dutch hospitals: results of a retrospective patient record review study". Quality and Safety in Health Care 18 (2009): 297-302.

11. Landrigan CP., et al. "Temporal Trends in Rates of Patient Harm Resulting from Medical Care". The New England Journal of Medicine 363 (2010): 2124-2134.

12. Classen DC., et al. "Global Trigger Tool» Shows That Adverse Events in Hospitals May Be Ten Times Greater Than Previously Measured". Health Affairs 30(2011): 4581-4589.

13. Deilkås ET., et al. "Monitoring adverse events in Norwegian hospitals from 2010 to 2013". BMJ Open 5(2015): 1-6.

14. Andrews LB., et al. "An alternative strategy for studying adverse events in medical care". Lancet 349.9048 (1997): 309313.

15. Wanzel KR., et al. "Complications on a general surgery service: incidence and reporting". Centre of Japanese Studies 43.2 (2000): 113-117.

16. Szlejf C., et al. "Medical adverse events in elderly hospitalized patients: A prospective study". Clinics (Sao Paulo) 67.11 (2012): 1247-1252.

17. McGuire HHJ., et al. "Measuring and managing quality of surgery. Statistical vs incidental approaches". The Archives of Surgery 127.6 (1992):733-737.
18. O'Neil AC., et al. "Physician reporting compared with medicalrecord review to identify adverse medical events". Annals of Internal Medicine 119.5 (1993):370-376.

19. Singh H., et al. "Primary care practitioners' views on test result management in EHR-enabled health systems: a national survey". Journal of the American Medical Informatics Association (2012):1-9.

20. Woods DM., et al. "Ambulatory care adverse events and preventable adverse events leading to a hospital admission". Quality and Safety in Health Care 16.2 (2007): 127-131.

21. Leap LL., et al. "The Nature of Adverse Events in Hospitalized Patients. Results of the Harvard Medical Practice Study II". The New England Journal of Medicine 324 (1991): 377-384.

22. Andrews JM., et al. "National Study on Hospitalisation-Related Adverse Events ENEAS 2005". Quality Plan of National Health System". Report (2006).

23. Campbell MJ., et al. "Developing a summary hospital mortality index: retrospective analysis in English hospitals over five years". British Medical Journal 344 (2012):1001-1012.

24. Wilson L., et al. "Perioperative Mortality in New Zealand: Fourth report of the Perioperative Mortality Review Committee". Report to the Health Quality and Safety Commission New Zealand (2015).

25. Hospital Trends in Canada. "Canadian Institute for Health Information". National Health Expenditure Database (2005).

26. Aiken LH., et al. "Nurse staffing and education and hospital mortality in nine European countries: a retrospective observational study". Lancet 26 (2014):1-7.

27. Jarman B., et al. "The hospital standardised mortality ratio: a powerful tool for Dutch hospitals to assess their quality of care?". Quality and Safety in Health Care 19 (2010): 9-13.

28. Makary MA and Daniel M. "Medical error-the third leading cause of death in the US". British Medical Journal 353.3 (2016): $1-5$.

29. Hall MJ., et al. "Trends in Inpatient Hospital Deaths: National Hospital Discharge Survey, 2000-2010 (U.S. DHHS - Centers for Disease Control and Prevention)". NCHS Data Brief (2013): 118.

30. Beuzekom M., et al. "Patient safety: latent risk factors". British Journal of Anaesthesia 105.1 (2010): 52-59. 
31. Lawton R., et al. "Identifying the latent failures underpinning medication administration errors: an exploratory study". Health Services Research 47.4 (2012): 1437-1459.

32. Reason J. "Human error: models and management". British Medical Journal 320 (2000): 768-770.

33. Hoffmann B and Rohe J. "Patient safety and error management”. Deutsches Ärzteblatt International 107.6 (2010): 92-99.

34. Mitchell R., et al. "A review of the use of human factors classification frameworks that identify causal factors for adverse events in the hospital setting". Ergonomics 57.10 (2014): 1443-1472.

35. Carayon P., et al. "Work system design for patient safety: the SEIPS model". Quality and safety in health care 15 (2006):150158.

36. Clancy C and Tornberg D. "Team STEPPS: Assuring optimal teamwork in clinical settings". American Journal of Medical Quality 22.3 (2007): 214-217.

37. Edmondson A. "Learning from failure in medical care: frequent opportunities, pervasive barriers". Quality and safety in health care 13.2 (2004):113-119.

38. Lyons M. "Should patients have a role in patient safety? A safety engineering view". Quality and safety in health care 16.2 (2007): 140-142.

39. Verstappen W., et al. "Patient safety improvement programmes for primary care. Review of a Delphi procedure and pilot studies by the LINNEAUS collaboration on patient safety in primary care". European Journal of General Practice 21.1 (2015): 50-55.

40. Molloy GJ and O'Boyle CA. “The SHEL model: a useful tool for analyzing and teaching the contribution of Human Factors to medical error". Academic Medicine 80.2 (2005):152-155.

41. Takayanagi $\mathrm{K}$ and Hagihara Y. "Revised sunflower-SHELL model--an analysis tool to ensure adverse-events' factor analysis and followed by patient safety strategy". J P N Hospital 25 (2007):11-18.

42. Pronovost P., et al. "Evaluation of the culture of safety: survey of clinicians and managers in an academic medical center". Quality and safety in health care 12 (2003): 405-410.
43. Lilford R., et al. "The measurement of active errors: methodological issues". Quality and safety in health care 12.2 (2003):118-1112.

44. Hibbert $\mathrm{P}$ and Williams $\mathrm{H}$. "The use of a global trigger tool to inform quality and safety in Australian general practice: a pilot study". Australian Family Physician 43.10 (2014): 723-726.

45. Michel Ph., et al. "Comparison of three methods for estimating rates of adverse events and rates of preventable adverse events in acute care hospitals". British Medical Journal 328.24 (2004): 199-202.

46. Pietra L., et al. "Medical errors and clinical risk management: state of the art". ACTA Otorhinolaryngological Italica 25(2005): 339-346.

47. Shaw R., et al. "Adverse events and nearmiss reporting in the NHS". Quality and safety in health care 14 (2005): 279-283.

48. Shikina IB., et al. "Problems of patients' safety assurance in modern medical care". Moscow, Publishing House Glossarium LLC (2006): 336.

49. Joint Commission International Accreditation Standards for Hospitals 6th Edition Including Standards for Academic Medical Center Hospitals (2017): 37.

50. Zadvornaya OL., et al. "Socio-economic aspects of medical errors and their consequences in medical organizations". MIR Modernization Innovation Research 10.1 (2019): 99-113.

\section{Volume 3 Issue 11 November 2019 (C) All rights are reserved by , Irina Shikina., et al.}

